\title{
RNA transcript expression of IGF-I/PI3K pathway components in regenerating skeletal muscle is sensitive to initial injury intensity
}

Ronald W. Matheny Jr. ${ }^{\text {a, \# }, \text { Christopher T. Carrigan }}{ }^{\mathrm{a}}$, Mary N. Abdalla ${ }^{\mathrm{a}, 1}$, Alyssa V. Geddis ${ }^{\mathrm{a}}$, Luis A. Leandry ${ }^{\mathrm{a}}$, Carlos A. Aguilar ${ }^{\mathrm{b}}$, Stuart S. Hobbs ${ }^{\mathrm{a}}$, and Maria L. Urso ${ }^{\mathrm{a}, 2}$

Running Title: IGF-I/PI3K RNA expression in regenerating muscle

${ }^{a}$ Military Performance Division, US Army Research Institute of Environmental Medicine, 15 Kansas Street, Building 42, Natick, MA, 01760 USA.

b Massachusetts Institute of Technology Lincoln Laboratory, 244 Wood St., Lexington, MA, 02420, USA.

${ }^{1}$ Present address: University of Massachusetts Medical School, Department of Molecular, Cell, and Cancer Biology, 364 Plantation St., Worcester, MA 01605

${ }^{2}$ Present address: Biocompatibles Inc., a BTG International group company, Five Tower Bridge, Suite 810, 300 Barr Harbor Drive West Conshohocken, PA, 19428-2998

\# To whom correspondence should be addressed: Ronald W. Matheny Jr., Military Performance Division, US Army Research Institute of Environmental Medicine, 10 General Greene Ave, Building 42, Natick, MA, 01760, USA, Tel.: (508) 233-5420; Fax: (508) 233-4195; email: ronald.w.matheny.civ@ mail.mil 


\begin{abstract}
$\underline{\text { Abstract }}$
Objective: Skeletal muscle regeneration is a complex process involving the coordinated input from multiple stimuli. Of these processes, actions of the insulin-like growth factor-I (IGF-I) and phosphoinositide 3-kinase (PI3K) pathways are vital; however, whether IGF-I or PI3K expression is modified during regeneration relative to initial damage intensity is unknown. The objective of this study was to determine whether mRNA expression of IGF-I/PI3K pathway components was differentially regulated during muscle regeneration in mice in response to traumatic injury induced by freezing of two different durations.
\end{abstract}

Design: Traumatic injury was imposed by applying a 6-mm diameter cylindrical steel probe, cooled to the temperature of dry ice $\left(-79^{\circ} \mathrm{C}\right)$, to the belly of the left tibialis anterior muscle of 12-week old C57BL/6J mice for either 5 seconds (5s) or 10 seconds (10s). The right leg served as the uninjured control. RNA was obtained from injured and control muscles following 3, 7, and 21 days recovery and examined by real-time PCR. Expression of transcripts within the IGF, $\mathrm{PI} 3 \mathrm{~K}$, and Akt families, as well as for myogenic regulatory factors and micro-RNAs were studied.

Results: Three days following injury, there was significantly increased expression of $\operatorname{Ig} f 1, \operatorname{Ig} f$, Igf1r, Igf2r, Pik3cb, Pik3cd, Pik3cg, Pik3rl, Pik3r5, Akt1, and Akt3 in response to either 5s or 10s injury compared to uninjured control muscle. There was a significantly greater expression of Pik3cb, Pik3cd, Pik3cg, Pik3r5, Aktl, and Akt3 in 10s injured muscle compared to 5s injured muscle. Seven days following injury, we observed significantly increased expression of Igfl, $I g f 2, P i k 3 c d$, and Pik3cg in injured muscle compared to control muscle in response to 10s freeze injury. We also observed significantly reduced expression of Igflr and miR-133a in response to 
5s freeze injury compared to control muscle, and significantly reduced expression of $C \mathrm{~km}, \mathrm{miR}-1$ and $m i R-133 a$ in response to 10 s freeze injury as compared to control. Twenty-one days following injury, 5 s freeze-injured muscle exhibited significantly increased expression of $I g f 2$, Igf2r, Pik3cg, Akt3, Myod1, Myog, Myf5, and miR-206 compared to control muscle, while 10s freeze-injured muscles showed significantly increased expression of $\operatorname{Igf2} 2 \operatorname{Igf} 2 r, P i k 3 c b, P i k 3 c d$, Pik3r5, Aktl, Akt3, and Myog compared to control. Expression of $m i R-1$ was significantly reduced in 10s freeze-injured muscle compared to control muscle at this time. There were no significant differences in RNA expression between $5 \mathrm{~s}$ and 10 s injury at either $7 \mathrm{~d}$ or $21 \mathrm{~d}$ recovery in any transcript examined.

Conclusions: During early skeletal muscle regeneration in mice, transcript expressions for some components of the IGF-I/PI3K pathway are sensitive to initial injury intensity induced by freeze damage.

Keywords: Skeletal muscle; Regeneration; Insulin-like growth factor; PI3K; Akt; RNA 


\section{Introduction}

Skeletal muscle repair and regeneration are complex processes that require the coordinated regulation of multiple intra-and extracellular stimuli [1]. A thorough understanding of the physiological, biochemical, and genetic processes that regulate skeletal muscle regeneration is necessary in order to develop treatments and strategies to accelerate recovery following injury. During the process of skeletal muscle repair, quiescent, muscle-specific resident stem cells known as satellite cells are activated and enter the cell cycle $[2,3,4]$. Once activated, these cells proliferate and differentiate, ultimately forming nascent myofibers $[5,6]$. A number of intracellular signaling molecules regulate these processes, and among them, insulinlike growth factor-I (IGF-I) is a central mediator [7].

IGF-I is a polypeptide hormone that plays a critical role in skeletal muscle development, repair, and regeneration $[8,9]$. IGF-I signal transduction is mediated through its cognate receptor (IGF-IR), and binding of IGF-I to IGF-IR instigates intracellular signaling cascades that regulate transcription, translation, survival, and differentiation [10,11]. A primary mediator of IGF signal transduction is the lipid and protein kinase phosphoinositide 3-kinase (PI3K). Class I PI3Ks are heterodimers composed of a regulatory and a catalytic subunit that catalyze the conversion of phosphatidylinositol $(4,5)$ bisphosphate $\left(\mathrm{PIP}_{2}\right)$ to phosphatidylinositol $(3,4,5)$ trisphosphate $\left(\mathrm{PIP}_{3}\right)$ at the cell membrane to promote $\mathrm{PIP}_{3}$-dependent signal transduction [12]. PI3K p110 catalytic isoforms $\alpha, \beta$, and $\delta$, and their common regulatory subunit $\mathrm{p} 85 \alpha$, are expressed in skeletal muscle $[13,14]$, whereas PI3K catalytic isoform $\gamma$ and its regulatory subunit (p101) are expressed primarily in immune cells [15]. PI3K p110 $\alpha$ and $\mathrm{p} 110 \beta$ have been shown to promote skeletal muscle development and to regulate metabolism [16,17,18]; however, little is known 
regarding their roles during muscle regeneration. Additionally, the role of p1 $10 \delta$ in skeletal muscle has been relatively unexplored.

While the IGF-I/PI3K pathway is known to play a role in skeletal muscle regeneration, little is known vis-à-vis the contribution or expression of the various PI3K isoforms. Moreover, the extent to which expression of IGF-I, PI3K, and other muscle-specific factors are modulated during regeneration relative to initial damage intensity is not known. Given this lack of knowledge, we performed a study to determine the degree to which IGF-I/PI3K transcript expressions were modified in regenerating skeletal muscle initially subjected to freeze injury of two different durations. The freeze injury model has previously been shown to promote sufficient damage to initiate the regenerative process, and work by Pavlath et al., [19], Kuang et al., [20], and Warren et al., [21,22] suggests that the regenerative response may be dependent on the duration of the initial injury. Indeed, these studies showed that regeneration was complete within 12-days following five seconds of freeze injury, but still incomplete 14-days following ten seconds of freeze injury. Based on these prior studies, we hypothesized that transcript expression of IGF/PI3K pathway components would be elevated to a greater degree in muscles exposed to 10 seconds of freeze injury than in muscles exposed to 5 seconds of freeze injury.

\section{$\underline{\text { Material and Methods }}$}

\section{Animals}

Ten-week-old, C57BL/6J male mice were obtained from the Jackson Laboratory (Bar Harbor, ME). Animal care and use procedures were conducted in accordance with the National Institutes 
of Health Guide for the Care and Use of Laboratory Animals in a facility accredited by the Association for the Assessment and Accreditation of Laboratory Animal Care. All animal experiments were conducted under the guidelines on humane use and care of laboratory animals for research and were approved by the Institutional Animal Care and Use Committee of the US Army Research Institute of Environmental Medicine (USARIEM). Following their arrival at the facility, mice were given two weeks to acclimate to their housing before initiation of experimentation. Measurements of body weight, food intake, and water intake were made daily. Mice were housed on a 12-h light/dark cycle, at ambient temperature $\left(25 \pm 1^{\circ} \mathrm{C}\right)$ and provided food and water ad libitum before and after all procedures.

\section{Traumatic Muscle Injury Model}

The traumatic injury model has been described in detail previously $[23,24,25]$. Briefly, while anesthetized, hindlimbs of mice were shaved and the left tibialis anterior (TA) muscle was exposed via a 1-cm-long incision in the skin overlying the muscle. A traumatic freeze injury was induced by applying a 6-mm diameter cylindrical steel probe, cooled to the temperature of dry ice $\left(-79^{\circ} \mathrm{C}\right)$, to the belly of the left TA muscle for either 5 seconds $(5 \mathrm{~s})$ or 10 seconds $(10 \mathrm{~s})$. The right leg served as the uninjured control. All injuries were performed by the same investigator. Following injury or sham procedure (incision only, no injury), the incisions were closed using a 6-0 silk suture (Ethicon, Piscataway, NJ). Mice were administered the analgesic buprenorphine $(0.1 \mathrm{mg} / \mathrm{kg} \mathrm{sc})$ and allowed to recover on a heating pad. Postsurgical body weight measurements were assessed daily following surgery to ensure adequate recovery. Mice were euthanized 3 days (3d), 7 days (7d) or 21 days (21d) post-injury using $\mathrm{CO}_{2}$ inhalation and exsanguination via cardiac puncture. TA muscles were dissected and snap frozen in liquid $\mathrm{N}_{2}$ and stored at $-80^{\circ} \mathrm{C}$. 
Uninjured control and freeze-injured TA muscles were obtained from a minimum of three and a maximum of six mice per time point and per injury duration. The numbers of mice used for each time, freeze duration, and transcript are shown in Supplemental Table S1.

\section{Tissue processing, RNA isolation, and real-time PCR}

Approximately $20 \mathrm{mg}$ tissue was homogenized in TRIzol reagent (Life Technologies, Carlsbad, CA) using a hand-held manual disruptor and RNA extraction was performed as described [26]. cDNA synthesis and real-time PCR were performed exactly as described previously [27].

Differences in transcript expressions were determined by the $2^{-\Delta \Delta C t}$ method with normalization to the level of Rps13 gene expression. Primers/probes for real-time PCR were purchased from Life Technologies: Igf1 (IGF-I) (cat \# Mm00439560_m1), Igf2 (IGF-II) (cat \# Mm00439564_m1), Igf1r (IGF-I receptor) (cat \# Mm008002831_m1), Igf2r (IGF-II receptor) (cat \#

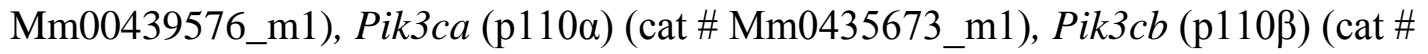

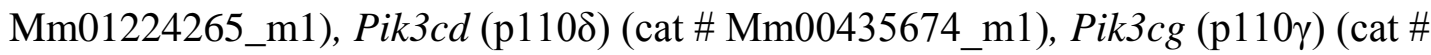
Mm0044038_m1), Pik3r1 (p85a) (cat \# Mm00803160_m1), Pik3r5 (p101) (cat \# Mm00805206_m1), Akt1 (Akt1) (cat \# Mm01331626_m1), Akt2 (Akt2) (cat \# Mm00545827_m1), Akt3 (Akt3) (cat \# Mm00442194_m1), Myog (Myogenin) (cat \# Mm00446194_m1), MyoD1 (Myogenic Differentiation 1) (cat \# Mm01203489_g1), Myf5 (Myogenic Factor 5) (cat \# Mm00435125_m1), Ckm (Creatine Kinase, muscle) (cat \# Mm01321487_m1), Rps13 (ribosomal protein S13) (cat \# Mm00850011_g1). 


\section{Analysis of microRNA}

cDNA was synthesized using the TaqMan MicroRNA Reverse Transcription Kit (\# 4366596, Life Technologies) and 5x RT Primers ( \#4427975 Life Technologies) using 10 ng RNA in a 15 $\mu \mathrm{L}$ final reaction volume according to the manufacturer's instructions. Real-time PCR was performed in a Stratagene Mx3005p (Agilent Technologies, Santa Clara, CA) using the following parameters: $95^{\circ} \mathrm{C}$ for 10 minutes, followed by 40 cycles of $95^{\circ} \mathrm{C}$ for 15 seconds and $60^{\circ} \mathrm{C}$ for 60 seconds. Primers/probes used in real-time PCR were as follows: $m i R-1$ (mmu-miR1a-3p; cat \# RT/TM 002222), miR-133a (mmu-miR-133a-3p; cat \# RT/TM 002246), miR-206 (mmu-miR-206-3p; cat \# RT/TM 000510).

\section{Statistics}

Statistical analysis was performed using GraphPad Prism 5 software. A two-way analysis of variance (ANOVA) was used to determine effects of time $\times$ damage intensity $(5 \mathrm{sec}$ vs. $10 \mathrm{sec}$ damage). Bonferroni multiple range test was performed post hoc to identify significant differences in intensities at each time point. A p-value $<0.05$ was considered significant. Data are presented as means \pm standard errors of the means (SEMs).

\section{$\underline{\text { Results }}$}

\section{IGFs}

Increased expression of IGF-I is associated with skeletal muscle regeneration in various models $[28,29,30]$; however, whether Igfl gene expression is influenced by initial injury intensity was not known. To address this question, we first examined the transcript expression of 
the IGF family including $I g f l, I g f 2, \operatorname{Ig} f 1 r$, and $I g f 2 r$ in regenerating muscle at 3, 7, and 21 days following either 5 seconds (5s) or 10 seconds (10s) freeze injury. Figure 1 shows that, three days (3d) following injury, significant increases in Igfl (4.1-fold; $\mathrm{p}<0.05)$ and $\operatorname{Igflr}(1.3$-fold; $\mathrm{p}<0.05)$ transcript expression were observed in 5s injured muscles compared to contralateral control, and significant increases in Igfl (6.6-fold; $\mathrm{p}<0.01)$, Igf2 (4.8-fold; $\mathrm{p}<0.05)$, and $\operatorname{Igf} 2 r$ (1.7-fold; $\mathrm{p}<0.01$ ) transcript expression were observed in 10 s injured muscles compared to contralateral control. Seven days (7d) following injury, we observed a 36\% reduction in expression of $I g f 1 r$ $(\mathrm{p}<0.01)$ in $5 \mathrm{~s}$ injured muscles compared to control, and significantly increased expression of IgfI (3.9-fold; $\mathrm{p}<0.05)$ and Igf2 (27.6-fold; $\mathrm{p}<0.05)$ in 10s injured muscles compared to control. Twenty-one days (21d) following injury, significant increases in Igf2 (4.9-fold; $\mathrm{p}<0.05)$ and $\operatorname{Igf2r}(1.4$-fold; $\mathrm{p}<0.05)$ transcript expression were observed in $5 \mathrm{~s}$ injured muscles compared to contralateral control. Significantly increased expression of $I g f 2$ and $I g f 2 r$ were also observed following 10s injury (2.6-fold and 1.5-fold, respectively; $\mathrm{p}<0.05$ for both). There was a significant main effect of time for $\operatorname{Igfl}(\mathrm{F}=6.595, \mathrm{p}=0.009), \operatorname{Igfl} \operatorname{lr}(\mathrm{F}=9.562, \mathrm{p}=0.002), \operatorname{Ig} 2$ $(\mathrm{F}=3.351, \mathrm{p}=0.019)$, and $\operatorname{Ig} f 2 r(\mathrm{~F}=5.196, \mathrm{p}=0.026)$. No significant differences between $5 \mathrm{~s}$ and 10s injury were noted in expression of any of these transcripts at any time point. There was a significant main effect if time for $\operatorname{Igfl} \operatorname{lr}(\mathrm{F}=11.02 ; \mathrm{p}=0.002)$ and $\operatorname{Ig} 2 r(\mathrm{~F}=4.83 ; \mathrm{p}=0.03)$ in the uninjured control muscle (Supplemental Figure S1A).

\section{PI3K}

PI3K is a principal mediator of IGF signaling; however, little is known regarding the transcript expression of the various catalytic and regulatory isoforms during muscle repair. 
Figure 2 shows that three days following injury, there was significantly increased transcript expression of Pik3cb (PI3K p1 10ß; 2-fold; $\mathrm{p}<0.05$ ) in 5s injured muscles compared to contralateral control, and significant increases in Pik3cb (2.9-fold; p<0.01), Pik3cd (PI3K p1108; 4.4-fold; $\mathrm{p}<0.01$ ), and Pik3rl (p85 $\alpha$; 2.2-fold; $\mathrm{p}<0.05$ ) transcript expressions in 10s injured muscles compared to contralateral control. There were significant main effects of time for Pik3cb $(\mathrm{F}=46.87, \mathrm{p}<0.001)$ and Pik3cd $(\mathrm{F}=13.71, \mathrm{p}<0.001)$, and a significant main effect of damage intensity for $\operatorname{Pik3cd}(\mathrm{F}=7.817, \mathrm{p}=0.016)$. A significant time $\times$ intensity interactive effect was present for $\operatorname{Pik} 3 c b(\mathrm{~F}=5.352, \mathrm{p}=0.021)$ and $\operatorname{Pik} 3 c d(\mathrm{~F}=6.441, \mathrm{p}=0.013)$. Significant differences in $P i k 3 c b$ and $P i k 3 c d$ transcript expression at $3 \mathrm{~d}$ were observed as a function of damage intensity ( $5 \mathrm{~s}$ vs. 10 s freeze injury), with a 1.5 -fold greater response in 10 s intensity than 5s intensity for $P i k 3 c b(\mathrm{p}<0.05)$, and a 2.8 -fold greater response in 10 s intensity than 5 s intensity for Pik3cd ( $\mathrm{p}<0.01)$. Seven days following injury, there was a $29 \%$ reduction in expression of Pik3cd (p<0.05), and 21 days following injury, expression of Pik3cb and Pik3cd were elevated by 1.4- and 1.5 -fold, respectively ( $<<0.05$ for both). No significant changes in expression of Pik3ca (PI3K p110 $\alpha)$ were noted at any observed time or damage intensity. There was a significant main effect of time for $P i k 3 c d(\mathrm{~F}=6.53 ; \mathrm{p}=0.012)$ in the uninjured control muscle (Supplemental Figure S1B).

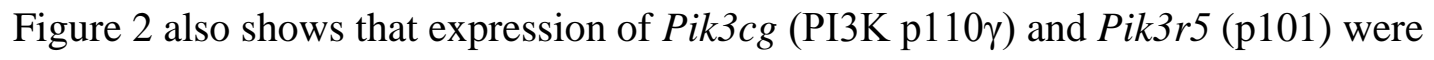
significantly elevated in regenerating muscle as compared to contralateral control at both $5 \mathrm{~s}$ (16fold and 20.5-fold, respectively; $\mathrm{p}<0.05$ for both) and 10s (47-fold and 52-fold, respectively; $\mathrm{p}<0.01$ for each) damage duration. There were significant main effects of time, intensity, and time $\times$ intensity for Pik3cg (time: F=27.13, p<0.001; intensity F=9.313, p=0.009; time $\times$ intensity: $\mathrm{F}=8.045, \mathrm{p}=0.005$ ) and $\operatorname{Pik} 3 r 5$ (time: $\mathrm{F}=24.32, \mathrm{p}<0.001$; intensity $\mathrm{F}=6.914, \mathrm{p}=0.019$; 
time $\times$ intensity: $\mathrm{F}=5.454, \mathrm{p}=0.017)$. Significant differences in Pik3cg and Pik3r5 transcript expression at $3 \mathrm{~d}$ were also observed as a function of damage intensity ( $5 \mathrm{~s}$ vs. $10 \mathrm{~s}$ freeze injury), with a 2.9-fold greater response in 10 s intensity than $5 \mathrm{~s}$ intensity for $P i k 3 \mathrm{cg}(\mathrm{p}<0.001)$, and a 2.5 fold greater response in 10 s intensity than 5 s intensity for $\operatorname{Pik} 3 r 5(\mathrm{p}<0.01)$. Seven days after injury, expression of $P i k 3 c g$ was elevated 5.8-fold in 10s regenerating muscle compared to contralateral control $(\mathrm{p}<0.05)$, and 21 days after injury, expression of Pik3cg was elevated 2.8fold in $5 \mathrm{~s}$ regenerating muscle ( $\mathrm{p}<0.05)$, and Pik3r5 expression was increased by 2 -fold in muscle subjected to 10 s freeze injury $(\mathrm{p}<0.05)$ compared to control. No significant differences were noted between $5 \mathrm{~s}$ and $10 \mathrm{~s}$ damage intensities at 7 or 21 days. There was a significant main effect of time for Pik3r5 (F=3.88; $\mathrm{p}=0.048)$ in the uninjured control muscle (Supplemental Figure S1C).

\begin{abstract}
Akt
One well-studied IGF/PI3K effector is the serine/threonine kinase Akt [31]. Akt regulates multiple processes in muscle, including myoblast proliferation, protein synthesis, and metabolism [32]. Three Akt isoforms have been identified in mammals (Akt1, Akt2, and Akt3), and distinct and redundant functions have been identified for each [32]. Akt has been shown to play a critical role in skeletal muscle formation and regeneration [33,34]; however, whether Akt isoforms are differentially expressed at the transcript level following various degrees of traumatic injury is not known. To address this, we examined the expression of $A k t 1, A k t 2$, and Akt3 during skeletal muscle regeneration following either $5 \mathrm{~s}$ or $10 \mathrm{~s}$ freeze injury. There was a statistically significant main effect of time for $A k t l(\mathrm{~F}=3.920, \mathrm{p}=0.049)$, and significant main
\end{abstract}


effects of time $(\mathrm{F}=5.572, \mathrm{p}=0.019)$, intensity $(\mathrm{F}=9.853, \mathrm{p}=0.009)$, and time $\times$ intensity $(\mathrm{F}=6.175$, $\mathrm{p}=0.014)$ for $A k t 3$. As Figure 3 shows, expression of $A k t 3$ was increased 3 -fold $(\mathrm{p}<0.05)$ compared to contralateral control three days after 10s injury intensity. Additionally, significant differences in damage intensity (5s vs. 10s freeze injury) were seen in transcript abundances of $A k t 1$ and $A k t 3$ at this time, with a 4.9-fold greater increase in 10 s intensity than in 5 s intensity for Akt1 $(\mathrm{p}<0.05)$ and a 2.5 -fold greater increase in 10 s intensity than in $5 \mathrm{~s}$ intensity for Akt3 $(\mathrm{p}<0.01)$. No differences were noted between injured and control legs in transcript expression of any Akt gene seven days after injury; however, 21 days after injury, expression of Akt1 was increased 1.6-fold in 10s injured muscle compared to control $(\mathrm{p}<0.001)$. Expression of $A k t 3$ was also increased 21 days after injury, demonstrating a 1.5-fold increase in 5s injured muscle, and 1.6-fold increase in 10s injured muscle compared to contralateral controls ( $\mathrm{p}<0.05$ for both). There was a significant main effect if time for $A k t 1(\mathrm{~F}=5.59 ; \mathrm{p}=0.02)$ and $A k t 3(\mathrm{~F}=5.55 ; \mathrm{p}=0.036)$ and a significant main effect of damage intensity for $A k t 2(\mathrm{~F}=4.29 ; \mathrm{p}=0.039)$ in the uninjured control muscle (Supplemental Figure S2A).

\section{Muscle regeneration markers}

To determine whether transcript expression of factors known to regulate muscle regeneration were affected by initial damage duration, we examined expressions of muscle creatine kinase (Ckm), MyoD (Myod1), myogenin (Myog), and Myf5 (Myf5). Results are presented in Figure 4. There was a significant main effect of time for $C k m(F=16.49, \mathrm{p}<0.001)$, Myodl $(\mathrm{F}=13.09, \mathrm{p}<0.001)$, and Myog $(\mathrm{F}=4.705, \mathrm{p}=0.031)$. Three days following injury, a 59\% decrease in $C k m(\mathrm{p}<0.01)$, and a 3.9-fold increase in Myodl transcript expression $(\mathrm{p}<0.05)$ was observed in 5s injured muscles compared to contralateral control. Additionally, a 58\% decrease 
in $\mathrm{Ckm}$ transcript expression was observed in 10s injured muscles compared to control, and significant increases in Myodl (2.7-fold; $\mathrm{p}<0.01$ ), Myog (36-fold; $\mathrm{p}<0.05)$, and Myf5 (1.9-fold; $\mathrm{p}<0.01)$ transcript expression were observed in 10s injured muscles compared to control muscles. Seven days after injury, transcript expression of $\mathrm{Ckm}$ was reduced $50 \%$ in $10 \mathrm{~s}$ injured muscle compared to uninjured control muscle $(\mathrm{p}<0.01)$. Twenty-one days following injury, expression of Myog was increased 4.6-fold ( $\mathrm{p}<0.05$ ), expression of Myodl was increased 1.3-fold ( $\mathrm{p}<0.001$ ), and expression of Myf5 was increased 1.6-fold $(\mathrm{p}<0.05)$ in $5 \mathrm{~s}$ injured muscle compared to control muscle. Myog expression was increased 1.9-fold in 10s injured muscle compared to contralateral control muscle 21 days after injury ( $\mathrm{p}<0.01)$. In the uninjured control muscle, there was a significant main effect of time for $\operatorname{Ckm}(\mathrm{F}=5.45 ; \mathrm{p}=0.019)$, Myog $(\mathrm{F}=3.901$; $\mathrm{p}=0.047)$, and Myodl $(\mathrm{F}=9.315 ; \mathrm{p}=0.004)$ (Supplemental Figure S2B).

We next examined whether the expression of select micro-RNAs (miRNAs) was altered during regeneration (Figure 5). miRNAs are short, non-coding RNAs that post-transcriptionally regulate RNA stability and translation. A number of miRNAs that influence myoblast proliferation, differentiation, and skeletal muscle regeneration have been identified, including miR-206 [35], miR-1 [36], and miR-133a [37]. We found that, of these miRNAs, there was a significant main effect of time for miR-206 ( $\mathrm{F}=4.808$, $\mathrm{p}=0.026)$. Figure 5 shows that three days following 10s injury, we observed a 3-fold increase in miR-206 ( $<<0.05)$, and a 31\% decrease in miR-1 $(\mathrm{p}<0.01)$ in injured muscles compared to contralateral control muscles. Seven days after injury, there was a 33\% decrease in expression of miR-133a in muscles exposed to $5 \mathrm{~s}$ injury, and a $39 \%$ reduction in muscles exposed to 10 s injury compared to control ( $<<0.05$ for both). Twenty-one days following injury, expression of miR-206 was increased 24-fold in 5s injured muscles compared to control muscles $(\mathrm{p}<0.05)$. There was a significant main effect of time for 
miR-1 $(\mathrm{F}=5.51 ; \mathrm{p}=0.019)$ and miR-133a $(\mathrm{F}=6.44 ; \mathrm{p}=0.011)$ in the uninjured control muscle (Supplemental Figure S2C).

\section{$\underline{\text { Discussion }}$}

Skeletal muscle regeneration is a multi-step, complex phenomenon requiring the orchestrated regulation of multiple processes. Our findings revealed that, of these processes, transcript expression of IGF/PI3K pathway components were sensitive to the intensity of the initial injury. In general, we found that the 10s injury intensity induced greater RNA responses than the 5 s injury intensity, particularly at the $3 \mathrm{~d}$ time point. The abundance of expressed transcripts is dependent on the contributions of a number of feedback and feed-forward loops; indeed, these loops regulate pre-mRNA splicing, nuclear export, RNA stability, and RNA degradation, thereby fine-tuning the amount of mature mRNA available to support translation. Our observations thus reflect the balance of these processes.

IGF-I and IGF-II have long been recognized as important mediators of myoblast proliferation, differentiation, and skeletal muscle regeneration $[8,9,30,38,39,40]$. Our results from this study showed that $I g f 1$ and $I g f 2$ transcripts were elevated in response to injury; however, there were no significant differences between 5 s and 10 s injury intensities, despite the nominally increased expression in 10 s injured muscles compared to $5 \mathrm{~s}$ injured muscles at $3 \mathrm{~d}$ and 7d (Figure 1). These data suggest that transcript expressions of IgfI and Igf2 may be nearmaximally stimulated during recovery following 5 s injury.

We found that expression of $P i k 3 c b$ and $P i k 3 c d$ in injured muscle was increased to the greatest degree $3 \mathrm{~d}$ following injury, and was sensitive to the initial intensity (10s injury 
promoted a greater response than $5 \mathrm{~s}$ injury; Figure 2 ). The $3 \mathrm{~d}$ time point is within the early phase of regeneration associated with myoblast proliferation, and is consistent with cellular models of myoblast proliferation that have demonstrated an essential role for $\mathrm{p} 110 \beta[27,41]$. Thus, increased $P i k 3 c b$ expression in 10 s injured muscle compared to 5 s injured muscle may reflect increased myoblast proliferation during this period of regeneration. Whether the observed increase in Pik3cd expression is also a reflection of increased myoblast proliferation during this period of regeneration is not clear. While $\mathrm{p} 110 \delta$ has been shown to exert noncatalytic functions in proliferating vascular smooth muscle cells [42], its role in myoblast proliferation is not known. However, p110 is expressed in neurons of adult mice, and reduced axonal regeneration in response to sciatic nerve crush injury was observed in mice expressing kinase-inactive p1108 (D910A) compared to control mice [43]. Whether the increased Pik3cd transcript expression detected in our samples was derived from skeletal muscle, neuronal tissue, or both is unknown; nonetheless, it is clear that $P i k 3 c d$ expression is significantly upregulated following 10 s freeze injury. Pik3cd expression was not significantly upregulated at any time following 5s freeze injury, suggesting that expression of $P i k 3 c d$ is sensitive to damage stimulus. Certainly, more research is necessary to determine the role of $P i k 3 c d$ and its gene product in skeletal muscle.

We also observed that expression of Pik3cg and Pik3r5 were highly elevated 3d postinjury after both $5 \mathrm{~s}$ and $10 \mathrm{~s}$ injury intensities, and that expression of Pik3cg and Pik3r5 were significantly higher in 10 s injured muscle than in 5 s injured muscle (Figure 2). Since p110 $\gamma$ is highly expressed in immune cells, and since a degenerative phase characterized by infiltration of phagocytic cells occurs shortly after injury, our observation that Pik3cg and Pik3r5 were elevated at this time suggests that the increased expression likely originates from infiltrating 
immune cells. The increased Pik3cg and Pik3r5 expression observed in the 10 s injured muscles compared to the $5 \mathrm{~s}$ injured muscles may represent the presence of elevated immune cells in response to the greater injury duration. It should be noted however, that we cannot definitively rule out a contribution from non-hematopoietic sources, as Pik3cg expression has been detected at low levels in skeletal muscle itself [44].

Distinct functions of Akt isoforms in skeletal muscle have been identified; for example, Akt1 has been shown to be the primary Akt isoform that promotes differentiation of cultured myoblasts [45], whereas Akt2 has been shown to be upregulated during differentiation and to participate in myotube maturation [46,47]. In response to IGF-I, Akt3 opposed oxidative stress in $\mathrm{C} 2 \mathrm{C} 12$ murine myoblasts [48]. In the present study, we found that expression of $A k t l$ and $A k t 3$ were significantly greater in $10 \mathrm{~s}$ injured muscles than in $5 \mathrm{~s}$ injured muscles $3 \mathrm{~d}$ post-injury (Figure 3). The significantly increased expression of $A k t l$ in the 10 s injured muscle is consistent with the importance of Akt1 in early myoblast differentiation; indeed, it would be expected that a greater injury stimulus would result in a greater responsiveness of $A k t 1$. However, the mechanism underlying the increased expression of $A k t 3$ does not appear to be as straightforward. Akt3 protein is highly expressed in the brain of adult mice but only weakly expressed in postmitotic adult skeletal muscle [49]; thus, it is possible that increased $A k t 3$ expression may originate from nascent myoblasts or from non-muscle cells present during this period of regeneration [50].

We found that muscle-specific developmental, regenerative, and miRNA transcript expressions did not statistically differ between $5 \mathrm{~s}$ and $10 \mathrm{~s}$ injury at any time point examined (Figures 4 and 5). One explanation for these findings is that, like $I g f I$ and $I g f 2$, expression of these molecules was already highly-stimulated following 5 s injury, possibly reaching an upper 
threshold of expression. One intriguing observation however, was that expression of $C k m$ was reduced in 10s injured muscle compared to control muscle at $3 \mathrm{~d}$ and $7 \mathrm{~d}$ following injury, and reduced in $5 \mathrm{~s}$ injured muscle compared to control muscle at $3 \mathrm{~d}$ following injury (Figure 4). This reduction in $\mathrm{Ckm}$ expression may initially appear counterintuitive, especially given that cellular models of myoblast differentiation report increased $C \mathrm{~km}$ mRNA, Creatine Kinase (CK) protein, and CK activity in various immortalized and primary muscle cell lines [27,46,51]. It should be kept in mind however, that the sequences of molecular events that occur in myoblast differentiation in cultured cells are similar to those that occur during muscle regeneration in vivo, and when viewed in this context, our results are complementary to cell-based models. For example, at the $3 \mathrm{~d}$ time following severe injury, injured muscle is composed of a number of different cell types (immune cells, fibro/adipogenic progenitor cells, endothelial cells), including proliferating myoblasts [50]; hence, the reduced abundance of $\mathrm{Ckm}$ transcripts in injured muscles compared to control muscles was likely secondary to the destruction of a large proportion of the original, $\mathrm{Ckm}$-expressing myofibers. By $7 \mathrm{~d}$ following injury, the injured tissue is composed predominantly of proliferating and differentiating muscle cells, which begin to express $C \mathrm{~km}$. Given this, it would be expected that expression of $\mathrm{Ckm}$ would be greater at $7 \mathrm{~d}$ following injury than at $3 \mathrm{~d}$ following injury because the destroyed tissue will have been sufficiently cleared, and nascent myoblasts will have begun to differentiate. Further, it would be expected that the regenerating muscle at the $21 \mathrm{~d}$ time point would possess more $C \mathrm{~km}$ than at the $7 \mathrm{~d}$ time point because terminal differentiation of myofibers will have occurred. Thus, similar to cell culture models of myoblast differentiation, regeneration following freeze injury is also characterized by an increase in $\mathrm{Ckm}$ expression, as resident myoblasts fuse and differentiate to form mature myofibers. It was also noteworthy that 10 s freeze-injured muscles showed significantly reduced 
$C k m$ transcript expression at $7 \mathrm{~d}$ compared to control, whereas $5 \mathrm{~s}$ freeze-injured muscles did not (Figure 4). The most obvious explanation of these findings is that $5 \mathrm{~s}$ freeze injury is less traumatic than 10s freeze injury, thereby allowing $C \mathrm{~km}$ levels in $5 \mathrm{~s}$ injured muscles to return to control levels at a faster rate than 10 s injured muscles.

Among the miRNA transcripts examined, miR-206 displayed the most dramatic changes in response to injury (Figure 5). This skeletal muscle-specific miRNA has been shown to stimulate muscle cell differentiation by suppressing genes that promote proliferation and prevent differentiation [52]. In vivo, miR-206 expression was significantly increased in skeletal muscle from five to 14-days following cardiotoxin injection [35], suggesting the importance of miR-206 during this period of the regenerative phase. Additionally, injection of double-stranded miR-206 into lacerated muscle resulted in enhanced muscle regeneration within one week of the injection as compared to injured muscle injected with a control RNA [53]. This previous report is noteworthy because we observed significantly increased miR-206 at $3 \mathrm{~d}$ post-injury in response to 10s freeze injury (Figure 5). Such a finding supports the existence of an early acute reparative response, or the initial rise leading to the sustained miR-206 expression levels we observed at $7 d$ and 21d. Overall, our data are consistent with a role for miR-206 in muscle regeneration and suggest that different modes of muscle injury may induce similar molecular responses, although differences in the severity of the initial injury may affect the magnitude of these responses.

We also observed that expression of miR-133a was altered in regenerating muscles. miR-133a has been previously shown to be involved in regulating IGF family molecules at the protein level, particularly IGF-IR. For example, in cultured C2C12 myoblasts, miR-133a expression was found to be reciprocally related to IGF-IR protein abundance through its translational repression of IGF-IR [54]. Moreover, IGF-I was found to stimulate miR-133a 
expression, which was itself identified as a participant in a negative feedback loop for IGF-1R signaling and expression [54]. These data suggest that an increase in IGF-I signaling leads to increased expression of miR-133a, which in turn, inhibits translation of IGF-IR. In this fashion, IGF-I can inhibit expression of its own receptor. Despite this relationship, we did not observe simultaneous increases in miR-133a expression and Igfl mRNA expression as would be expected if the relationship between the expressions of these two transcripts was directly correlated. However, since the expression of miR-133a is dependent on signaling by the mature IGF-I peptide and not the expression of Igfl mRNA, expression of miR-133a is subject to the rate of translation, secretion, receptor binding, and turnover of mature IGF-I protein rather than Igfl transcript.

Reciprocal regulation between miR-1 and IGF-I protein expression has been observed in skeletal and cardiac muscle [55]. This reciprocal regulation resulted from miR-1mediated inhibition of IGF-I protein, and IGF-I signaling-mediated inhibition of miR-1[56]. Thus, high levels of IGF-I protein are expected to be associated with low levels of miR-1. We did not observe a reciprocal relationship between expressions of these two transcripts at all time points in our study. For example, while the decreased expression of miR-1 at $3 \mathrm{~d}$ following $10 \mathrm{~s}$ freeze injury did coincide with increased Igfl transcript expression, we did not observe a similar inverse relationship in muscles subjected to $5 \mathrm{~s}$ freeze injury at $7 \mathrm{~d}$ following injury, nor in muscles subjected to10s freeze injury at $21 \mathrm{~d}$ following injury. Interpretation of these findings is somewhat confounded by the absence of data reflecting IGF-I peptide levels in the regenerating muscles. Additionally, it is possible that more complex regulatory mechanisms may be active during regeneration that modulate miR-1 and $I g f l$ expression than described by the studies cited above, which did not use an injury model. 
In conclusion, our results identify injury intensity-dependent responses in transcript expression of IGF/PI3K pathway components in regenerating skeletal muscle. These responses were most apparent in PI3K (Pik3cb, Pik3cd, Pik3cg, Pik3r5) and Akt (Akt1, Akt3) isoforms, thus revealing injury intensity-dependent, isoform-specific expressions of these genes during muscle repair.

\section{Acknowledgements}

This work was supported by funding from U.S. Army Research Area directorate III, Military Research and Materiel Command (to M.L.U. and R.W.M.). C.T.C., A.V.G., and M.N.A. were supported by appointments to the Postgraduate Research Participation Program at the U.S. Army Research Institute of Environmental Medicine administered by the Oak Ridge Institute for Science and Education through interagency agreement between the U.S. Department of Energy and U.S. Army Medical Research and Materiel Command. The authors wish to thank Dr. Earl Wogy of the Brandywine Center for Aging Studies for helpful discussions during the preparation of this manuscript.

The views, opinions, and/or findings in this report are those of the authors, and should not be construed as an official Department of the Army position, policy, or decision, unless so designated by other official documentation.

\section{Declaration of Interest}

Conflicts of interest: none. 


\section{$\underline{\text { References }}$}

[1] M. Karalaki, S. Fili, A. Philippou, M. Koutsilieris, Muscle regeneration: cellular and molecular events, In Vivo 23 (2009) 779-796.

[2] S. Kuang, M.A. Rudnicki, The emerging biology of satellite cells and their therapeutic potential, Trends Mol Med 14 (2008) 82-91.

[3] A. Mauro, Satellite cell of skeletal muscle fibers, J Biophys Biochem Cytol 9 (1961) 493495.

[4] E. Schultz, M.C. Gibson, T. Champion, Satellite cells are mitotically quiescent in mature mouse muscle: an EM and radioautographic study, J Exp Zool 206 (1978) 451-456.

[5] X. Shi, D.J. Garry, Muscle stem cells in development, regeneration, and disease, Genes Dev 20 (2006) 1692-1708.

[6] K. Walsh, H. Perlman, Cell cycle exit upon myogenic differentiation, Curr Opin Genet Dev 7 (1997) 597-602.

[7] A. Philippou, A. Halapas, M. Maridaki, M. Koutsilieris, Type I insulin-like growth factor receptor signaling in skeletal muscle regeneration and hypertrophy, J Musculoskelet Neuronal Interact 7 (2007) 208-218.

[8] D.W. Hammers, R.W. Matheny, Jr., C. Sell, M.L. Adamo, T.J. Walters, J.S. Estep, R.P. Farrar, Impairment of IGF-I expression and anabolic signaling following ischemia/reperfusion in skeletal muscle of old mice, Exp Gerontol 46 (2011) 265-272.

[9] D.W. Hammers, E.K. Merritt, R.W. Matheny, Jr., M.L. Adamo, T.J. Walters, J.S. Estep, R.P. Farrar, Functional deficits and insulin-like growth factor-I gene expression following 
tourniquet-induced injury of skeletal muscle in young and old rats, J Appl Physiol 105 (2008) 1274-1281.

[10] J.I. Jones, D.R. Clemmons, Insulin-like growth factors and their binding proteins: biological actions, Endocr Rev 16 (1995) 3-34.

[11] D.Z. Ewton, J.R. Florini, Effects of the somatomedins and insulin on myoblast differentiation in vitro, Dev Biol 86 (1981) 31-39.

[12] B. Vanhaesebroeck, M.D. Waterfield, Signaling by distinct classes of phosphoinositide 3kinases, Exp Cell Res 253 (1999) 239-254.

[13] B. Geering, P.R. Cutillas, G. Nock, S.I. Gharbi, B. Vanhaesebroeck, Class IA phosphoinositide 3-kinases are obligate p85-p110 heterodimers, Proc Natl Acad Sci U S A 104 (2007) 7809-7814.

[14] R.W. Matheny, Jr., M.L. Adamo, Effects of PI3K catalytic subunit and Akt isoform deficiency on mTOR and p70S6K activation in myoblasts, Biochem Biophys Res Commun 390 (2009) 252-257.

[15] L. Stephens, A. Smrcka, F.T. Cooke, T.R. Jackson, P.C. Sternweis, P.T. Hawkins, A novel phosphoinositide 3 kinase activity in myeloid-derived cells is activated by G protein beta gamma subunits, Cell 77 (1994) 83-93.

[16] L.C. Foukas, M. Claret, W. Pearce, K. Okkenhaug, S. Meek, E. Peskett, S. Sancho, A.J. Smith, D.J. Withers, B. Vanhaesebroeck, Critical role for the p110alpha phosphoinositide-3-OH kinase in growth and metabolic regulation, Nature 441 (2006) 366-370. 
[17] R.W. Matheny, Jr., A.V. Geddis, M.N. Abdalla, L.A. Leandry, Phosphatidylinositol 3kinase p110alpha mediates phosphorylation of AMP-activated protein kinase in myoblasts, Biochem Biophys Res Commun 469 (2016) 1117-1122.

[18] S. Jia, Z. Liu, S. Zhang, P. Liu, L. Zhang, S.H. Lee, J. Zhang, S. Signoretti, M. Loda, T.M. Roberts, J.J. Zhao, Essential roles of PI(3)K-p110beta in cell growth, metabolism and tumorigenesis, Nature 454 (2008) 776-779.

[19] G.K. Pavlath, D. Thaloor, T.A. Rando, M. Cheong, A.W. English, B. Zheng, Heterogeneity among muscle precursor cells in adult skeletal muscles with differing regenerative capacities, Dev Dyn 212 (1998) 495-508.

[20] W. Kuang, H. Xu, J.T. Vilquin, E. Engvall, Activation of the lama2 gene in muscle regeneration: abortive regeneration in laminin alpha2-deficiency, Lab Invest 79 (1999) 1601-1613.

[21] G.L. Warren, T. Hulderman, D. Mishra, X. Gao, L. Millecchia, L. O'Farrell, W.A. Kuziel, P.P. Simeonova, Chemokine receptor CCR2 involvement in skeletal muscle regeneration, FASEB J 19 (2005) 413-415.

[22] G.L. Warren, M. Summan, X. Gao, R. Chapman, T. Hulderman, P.P. Simeonova, Mechanisms of skeletal muscle injury and repair revealed by gene expression studies in mouse models, J Physiol 582 (2007) 825-841.

[23] B.R. Barnes, E.R. Szelenyi, G.L. Warren, M.L. Urso, Alterations in mRNA and protein levels of metalloproteinases-2, -9, and -14 and tissue inhibitor of metalloproteinase-2 responses to traumatic skeletal muscle injury, Am J Physiol Cell Physiol 297 (2009) C1501-1508. 
[24] M.L. Urso, E.R. Szelenyi, G.L. Warren, B.R. Barnes, Matrix metalloprotease-3 and tissue inhibitor of metalloprotease-1 mRNA and protein levels are altered in response to traumatic skeletal muscle injury, Eur J Appl Physiol 109 (2010) 963-972.

[25] M.L. Urso, R. Wang, E.J. Zambraski, B.T. Liang, Adenosine A3 receptor stimulation reduces muscle injury following physical trauma and is associated with alterations in the MMP/TIMP response, J Appl Physiol (1985) 112 (2012) 658-670.

[26] R.W. Matheny, Jr., M.L. Adamo, PI3K p110 alpha and p110 beta have differential effects on Akt activation and protection against oxidative stress-induced apoptosis in myoblasts, Cell Death Differ 17 (2010) 677-688.

[27] R.W. Matheny, Jr., M.A. Riddle-Kottke, L.A. Leandry, C.M. Lynch, M.N. Abdalla, A.V. Geddis, D.R. Piper, J.J. Zhao, Role of phosphoinositide 3-OH kinase p110beta in skeletal myogenesis, Mol Cell Biol 35 (2015) 1182-1196.

[28] A. Musaro, K. McCullagh, A. Paul, L. Houghton, G. Dobrowolny, M. Molinaro, E.R. Barton, H.L. Sweeney, N. Rosenthal, Localized Igf-1 transgene expression sustains hypertrophy and regeneration in senescent skeletal muscle, Nat Genet 27 (2001) 195-200.

[29] D.W. Hammers, V. Rybalko, M. Merscham-Banda, P.L. Hsieh, L.J. Suggs, R.P. Farrar, Anti-inflammatory macrophages improve skeletal muscle recovery from ischemiareperfusion, J Appl Physiol (1985) 118 (2015) 1067-1074.

[30] D. Edwall, M. Schalling, E. Jennische, G. Norstedt, Induction of insulin-like growth factor I messenger ribonucleic acid during regeneration of rat skeletal muscle, Endocrinology 124 (1989) 820-825. 
[31] S.P. Staal, J.W. Hartley, W.P. Rowe, Isolation of transforming murine leukemia viruses from mice with a high incidence of spontaneous lymphoma, Proc Natl Acad Sci U S A 74 (1977) 3065-3067.

[32] B.D. Manning, L.C. Cantley, AKT/PKB signaling: navigating downstream, Cell 129 (2007) $1261-1274$.

[33] G. Pallafacchina, E. Calabria, A.L. Serrano, J.M. Kalhovde, S. Schiaffino, A protein kinase B-dependent and rapamycin-sensitive pathway controls skeletal muscle growth but not fiber type specification, Proc Natl Acad Sci U S A 99 (2002) 9213-9218.

[34] J. Tureckova, E.M. Wilson, J.L. Cappalonga, P. Rotwein, Insulin-like growth factormediated muscle differentiation: collaboration between phosphatidylinositol 3-kinaseAkt-signaling pathways and myogenin, J Biol Chem 276 (2001) 39264-39270.

[35] N. Liu, A.H. Williams, J.M. Maxeiner, S. Bezprozvannaya, J.M. Shelton, J.A. Richardson, R. Bassel-Duby, E.N. Olson, microRNA-206 promotes skeletal muscle regeneration and delays progression of Duchenne muscular dystrophy in mice, J Clin Invest 122 (2012) 2054-2065.

[36] J.F. Chen, E.M. Mandel, J.M. Thomson, Q. Wu, T.E. Callis, S.M. Hammond, F.L. Conlon, D.Z. Wang, The role of microRNA-1 and microRNA-133 in skeletal muscle proliferation and differentiation, Nat Genet 38 (2006) 228-233.

[37] Y. Luo, X. Wu, Z. Ling, L. Yuan, Y. Cheng, J. Chen, C. Xiang, microRNA133a targets Foxl2 and promotes differentiation of $\mathrm{C} 2 \mathrm{C} 12$ into myogenic progenitor cells, DNA Cell Biol 34 (2015) 29-36.

[38] R.W. Matheny, Jr., B.C. Nindl, Loss of IGF-IEa or IGF-IEb impairs myogenic differentiation, Endocrinology 152 (2011) 1923-1934. 
[39] J.R. Florini, D.Z. Ewton, K.A. Magri, F.J. Mangiacapra, IGFs and muscle differentiation, Adv Exp Med Biol 343 (1993) 319-326.

[40] J.R. Florini, K.A. Magri, D.Z. Ewton, P.L. James, K. Grindstaff, P.S. Rotwein, "Spontaneous" differentiation of skeletal myoblasts is dependent upon autocrine secretion of insulin-like growth factor-II, J Biol Chem 266 (1991) 15917-15923.

[41] R.W. Matheny, Jr., C.M. Lynch, L.A. Leandry, Enhanced Akt phosphorylation and myogenic differentiation in PI3K p110beta-deficient myoblasts is mediated by PI3K p110alpha and mTORC2, Growth Factors 30 (2012) 367-384.

[42] M. Vantler, J. Jesus, O. Leppanen, M. Scherner, E.M. Berghausen, L. Mustafov, X. Chen, T. Kramer, M. Zierden, M. Gerhardt, H. Ten Freyhaus, F. Blaschke, A. Sterner-Kock, S. Baldus, J.J. Zhao, S. Rosenkranz, Class IA Phosphatidylinositol 3-Kinase Isoform p110alpha Mediates Vascular Remodeling, Arterioscler Thromb Vasc Biol 35 (2015) 1434-1444.

[43] B.J. Eickholt, A.I. Ahmed, M. Davies, E.A. Papakonstanti, W. Pearce, M.L. Starkey, A. Bilancio, A.C. Need, A.J. Smith, S.M. Hall, F.P. Hamers, K.P. Giese, E.J. Bradbury, B. Vanhaesebroeck, Control of axonal growth and regeneration of sensory neurons by the p110delta PI 3-kinase, PLoS One 2 (2007) e869.

[44] B. Stoyanov, S. Volinia, T. Hanck, I. Rubio, M. Loubtchenkov, D. Malek, S. Stoyanova, B. Vanhaesebroeck, R. Dhand, B. Nurnberg, et al., Cloning and characterization of a G protein-activated human phosphoinositide-3 kinase, Science 269 (1995) 690-693.

[45] E.M. Wilson, P. Rotwein, Selective control of skeletal muscle differentiation by Akt1, J Biol Chem 282 (2007) 5106-5110. 
[46] S. Gardner, M. Anguiano, P. Rotwein, Defining Akt actions in muscle differentiation, Am J Physiol Cell Physiol 303 (2012) C1292-1300.

[47] P. Rotwein, E.M. Wilson, Distinct actions of Akt1 and Akt2 in skeletal muscle differentiation, J Cell Physiol 219 (2009) 503-511.

[48] R.W. Matheny, Jr., M.L. Adamo, Role of Akt isoforms in IGF-I-mediated signaling and survival in myoblasts, Biochem Biophys Res Commun 389 (2009) 117-121.

[49] R.M. Easton, H. Cho, K. Roovers, D.W. Shineman, M. Mizrahi, M.S. Forman, V.M. Lee, M. Szabolcs, R. de Jong, T. Oltersdorf, T. Ludwig, A. Efstratiadis, M.J. Birnbaum, Role for Akt3/protein kinase Bgamma in attainment of normal brain size, Mol Cell Biol 25 (2005) 1869-1878.

[50] C.F. Bentzinger, Y.X. Wang, N.A. Dumont, M.A. Rudnicki, Cellular dynamics in the muscle satellite cell niche, EMBO Rep 14 (2013) 1062-1072.

[51] A.U. Trendelenburg, A. Meyer, D. Rohner, J. Boyle, S. Hatakeyama, D.J. Glass, Myostatin reduces Akt/TORC1/p70S6K signaling, inhibiting myoblast differentiation and myotube size, Am J Physiol Cell Physiol 296 (2009) C1258-1270.

[52] G.D. Ma, Y.J. Wang, Y. Li, L.L. Cui, Y.J. Zhao, B. Zhao, K.S. Li, MiR-206, a Key Modulator of Skeletal Muscle Development and Disease, International Journal of Biological Sciences 11 (2015) 345-352.

[53] T. Nakasa, M. Ishikawa, M. Shi, H. Shibuya, N. Adachi, M. Ochi, Acceleration of muscle regeneration by local injection of muscle-specific microRNAs in rat skeletal muscle injury model, Journal of Cellular and Molecular Medicine 14 (2010) 2495-2505.

[54] M.B. Huang, H. Xu, S.J. Xie, H. Zhou, L.H. Qu, Insulin-Like Growth Factor-1 Receptor Is Regulated by microRNA-133 during Skeletal Myogenesis, Plos One 6 (2011). 
[55] H.J. Jung, Y. Suh, Regulation of IGF -1 signaling by microRNAs, Front Genet 5 (2014) 472.

[56] L. Elia, R. Contu, M. Quintavalle, F. Varrone, C. Chimenti, M.A. Russo, V. Cimino, L. De Marinis, A. Frustaci, D. Catalucci, G. Condorelli, Reciprocal Regulation of MicroRNA-1 and Insulin-Like Growth Factor-1 Signal Transduction Cascade in Cardiac and Skeletal Muscle in Physiological and Pathological Conditions, Circulation 120 (2009) 2377-2385. 


\section{Figure Legends}

\section{Figure 1. Expression of IGF family transcripts in regenerating tibialis anterior following}

two damage intensities. The left tibialis anterior (TA) muscles of mice were subjected to freeze injury for 5 seconds $(5 \mathrm{sec})$ or 10 seconds $(10 \mathrm{sec})$ followed by 3,7 , or 21 days recovery as described in the Materials and Methods section. RNA was extracted from the injured, left TA muscle and from the right, uninjured contralateral TA muscle which served as the control for each individual mouse. Real-time PCR was performed using the indicated primers/probes; expression levels were then normalized to Rps 13 expression and expressed relative to the uninjured, control TA. Data represent means \pm SEMs from 3-6 mice per condition; see Supplemental Table S1 for exact numbers; *, $\mathrm{P}<0.05 ; * *, \mathrm{P}<0.01 ; * * *, \mathrm{P}<0.001$.

\section{Figure 2. Expression of PI3K catalytic and regulatory transcripts in regenerating tibialis} anterior following two damage intensities. Freeze injury and RNA recovery were performed as described in Figure 1. Real-time PCR was performed using the indicated primers/probes and expression levels were then normalized to Rps 13 expression and expressed relative to the uninjured, control TA. Data represent means \pm SEMs, and a horizontal bar indicates a significant difference between $5 \mathrm{~s}$ and 10 s freeze injury durations $(n=3-6$ mice per condition;

Supplemental Table S1 contains exact numbers; *, $\mathrm{P}<0.05 ; * *, \mathrm{P}<0.01 ; * * *, \mathrm{P}<0.001)$. 
Figure 3. Expression of Akt transcripts in regenerating tibialis anterior following two damage intensities. Freeze injury and RNA recovery were performed as described in Figure 1. Real-time PCR was performed to detect transcript levels of $A k t 1, A k t 2$, and $A k t 3$, and expression levels were then normalized to Rps 13 expression and expressed relative to the uninjured, control TA. Data represent means \pm SEMs, and a horizontal bar indicates a significant difference between $5 \mathrm{~s}$ and 10 s freeze injury durations $(\mathrm{n}=3$ - 6 mice per condition; see Supplemental Table S1 for exact numbers; *, $\mathrm{P}<0.05 ; * *, \mathrm{P}<0.01)$.

Figure 4. Expression of myogenic transcripts in regenerating tibialis anterior following two damage intensities. Freeze injury and RNA recovery were performed as described in Figure 1. Real-time PCR was performed using the indicated primers/probes and expression levels were then normalized to Rps13 expression and expressed relative to the uninjured, control TA. Data represent means \pm SEMs from $3-6$ mice per condition; Supplemental Table S1 provides exact numbers; *, $\mathrm{P}<0.05 ; * *, \mathrm{P}<0.01 ; * * *, \mathrm{P}<0.001$.

\section{Figure 5. microRNA expression in regenerating tibialis anterior following two damage}

intensities. Freeze injury and RNA recovery were performed as described in Figure 1. Realtime PCR was performed to detect $m i R-206, m i R-1$, and $m i R-133 a$ and expression levels were then normalized to Rps 13 expression and expressed relative to the uninjured, control TA. Data represent means \pm SEMs from $3-6$ mice per condition; see Supplemental Table S1 for exact numbers; *, $\mathrm{P}<0.05 ; * *, \mathrm{P}<0.01 ; * * *, \mathrm{P}<0.001$. 


\section{Igf1}
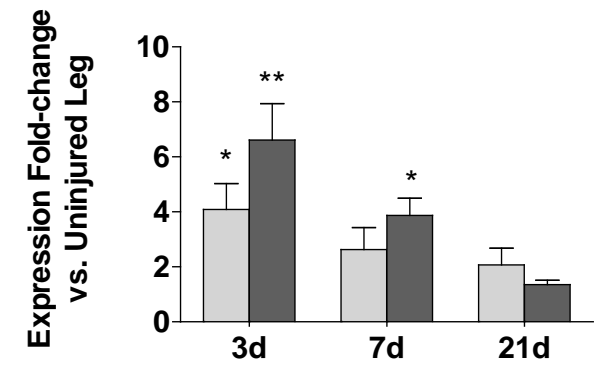

Igf1r

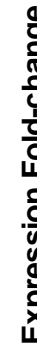

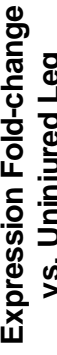

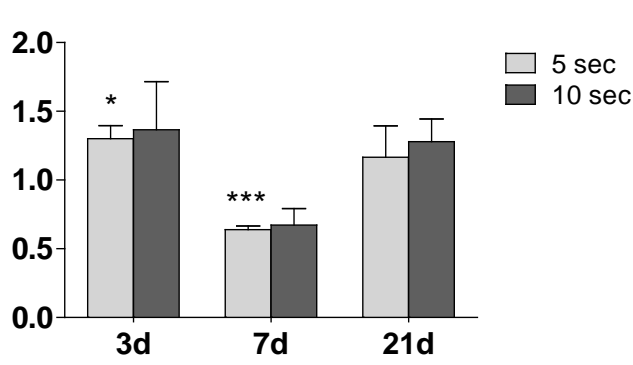

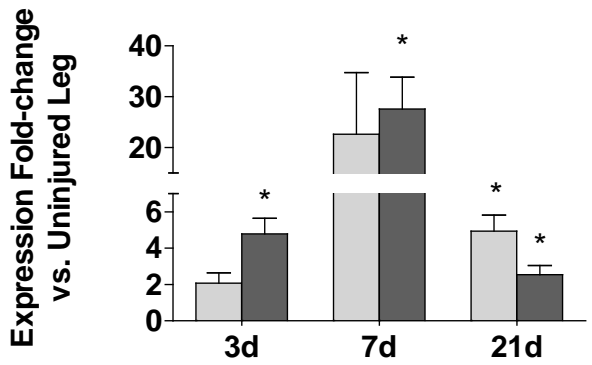

Igf2r

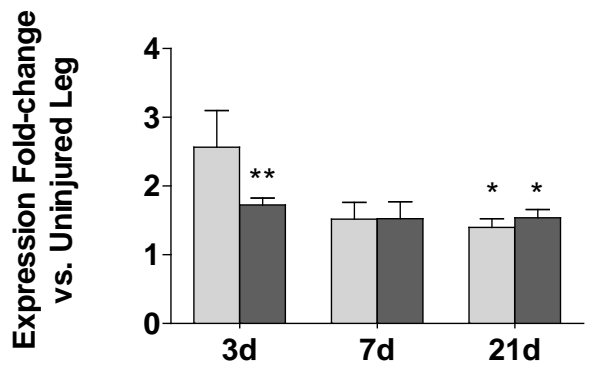

$\square 5 \mathrm{sec}$

$10 \mathrm{sec}$

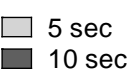



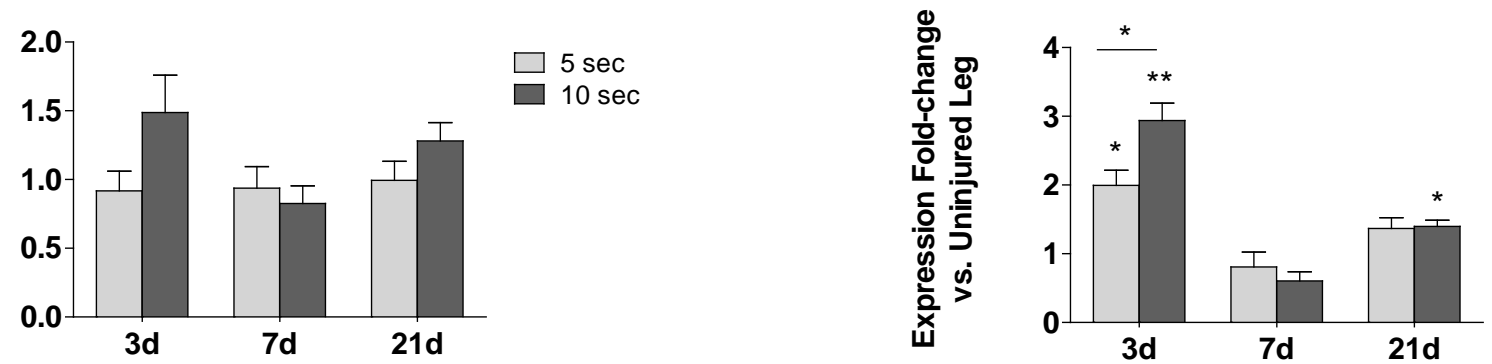

Pik3cd

Pik3r1
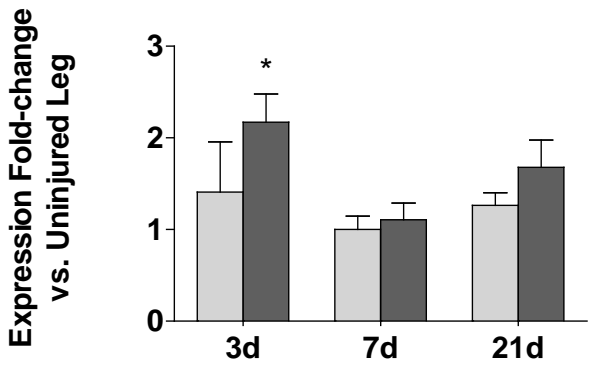
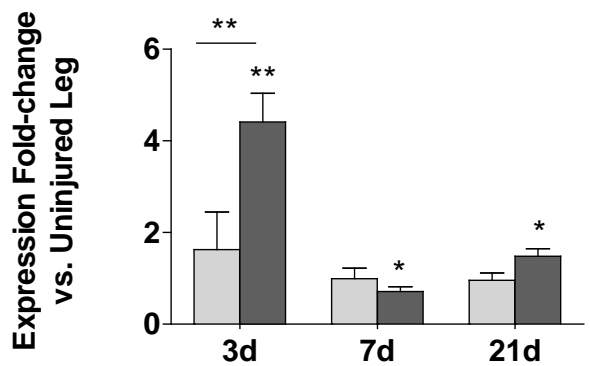

Pik3cg

$\square 5 \mathrm{sec}$

$\square 10 \mathrm{sec}$

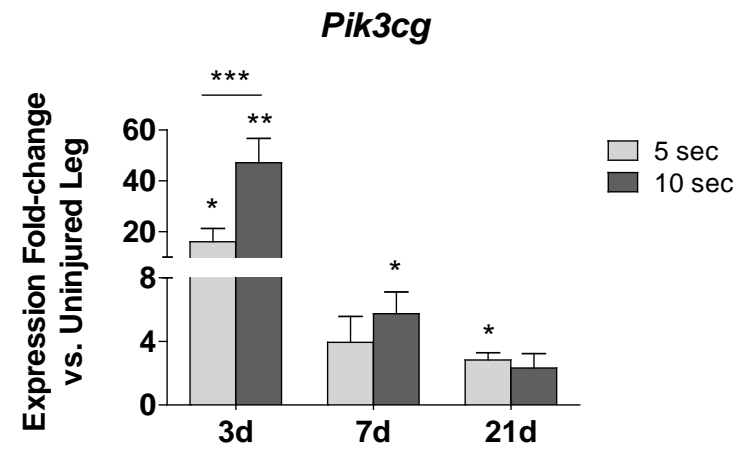

Pik3r5

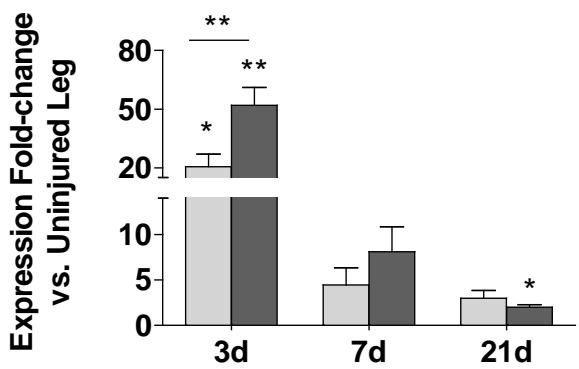

$\square 5 \mathrm{sec}$

$10 \mathrm{sec}$ 


\section{Akt1}

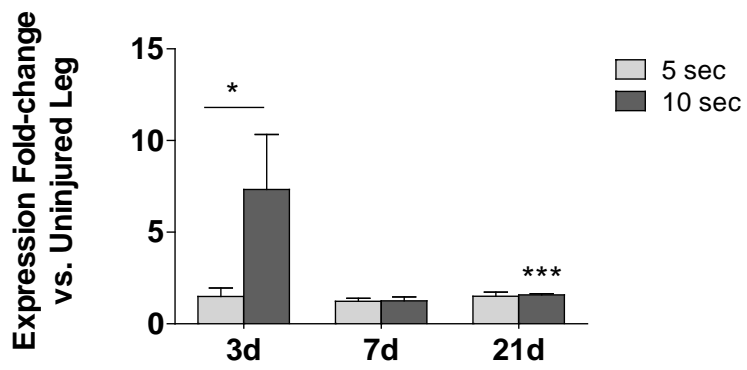

Akt2
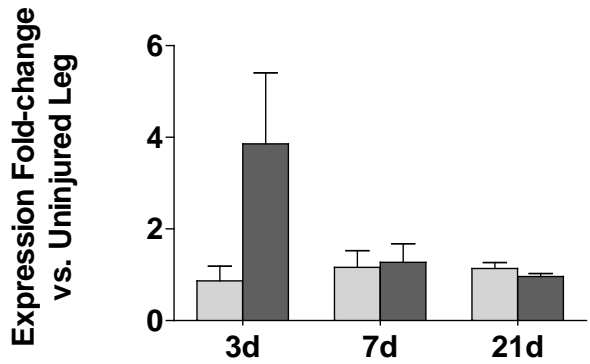

$\square 5 \mathrm{sec}$

$\square 10 \mathrm{sec}$

Akt3

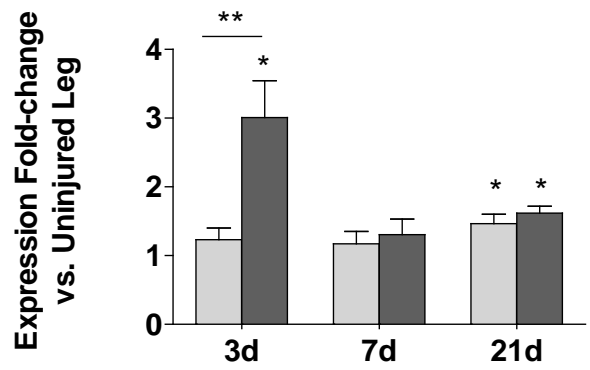




\section{Ckm}

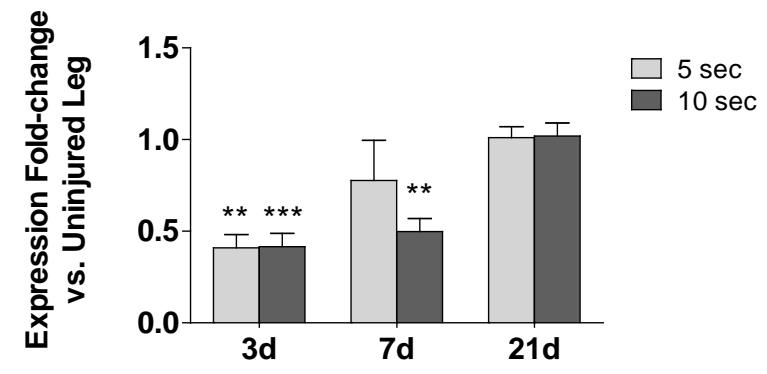

Myog

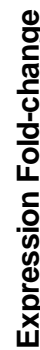

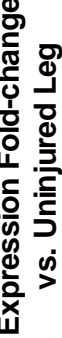

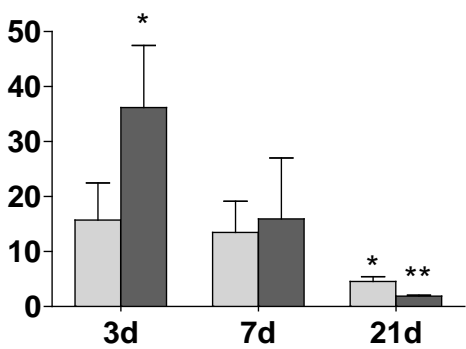

Myod1
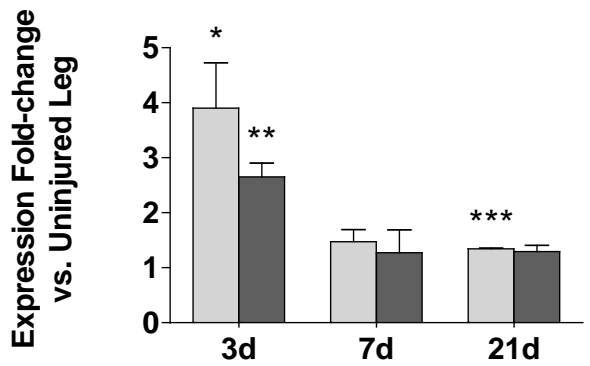

Myf5

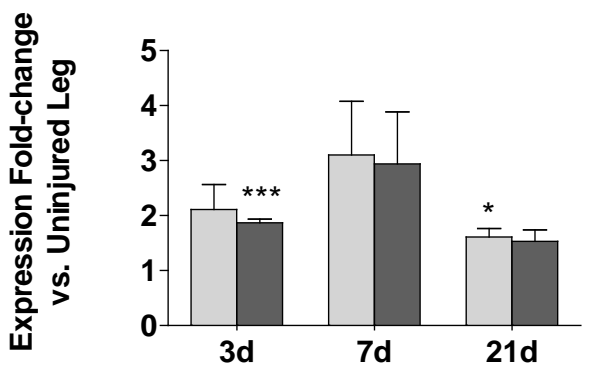

$5 \mathrm{sec}$ $10 \mathrm{sec}$

$\square 5 \mathrm{sec}$ $10 \mathrm{sec}$ 
miR-206

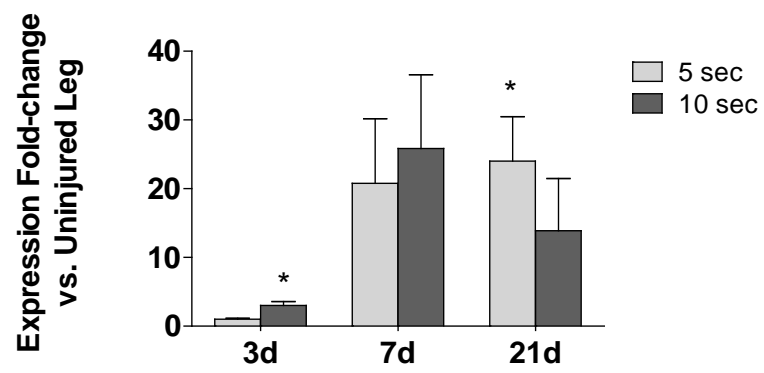

miR-1

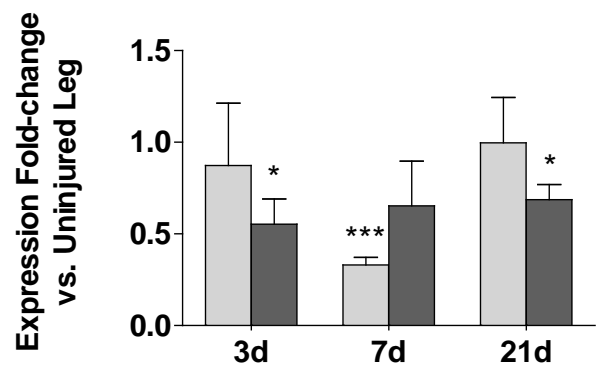

miR-133a

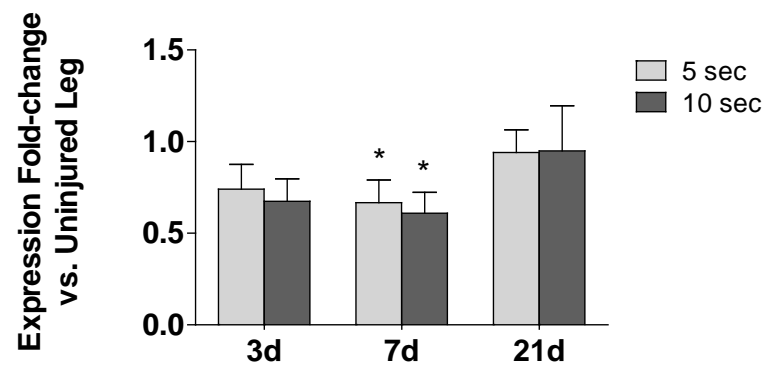

